\title{
Analysis on the Impact of Big Data on Management Accounting
}

\author{
Ruihan Yang* \\ University of Nottingham, Ningbo 315100, China \\ *Corresponding author: Ruihan Yang, biyry1@nottingham.edu.cn
}

\begin{abstract}
In recent years, big data has developed rapidly, and it would have a specific impact on the development of management accounting. In order to ensure the smooth development of management accounting, it is necessary to recognize the influence of big data on it and scientifically use the essential advantages of big data. By exploring and analyzing the main characteristics of big data, the article describes the impact of big data on management accounting and puts forward effective strategies to efficiently carry out management accounting under the environment of big data.
\end{abstract}

Keywords: Internet; Big data; Economy; Management accounting

Publication date: August 2021; Online publication: August 30, 2021

\section{Introduction}

Under the background of big data, previous production factors, production tools, organizational behaviors, and management accounting behaviors of companies have undergone significant changes. For this reason, it is vital to make appropriate adjustments to management accounting and systematically innovate management accounting behaviors to give full play to the critical value of management accounting itself. If companies desire to achieve this goal, they need to have a deep understanding on the impact of big data on management accounting.

\section{Main characteristics of big data}

In the early stage, International Business Machines (IBM) has summarized the four V's: variety, value, volume, and velocity, which reflect the characteristics of big data. In big data, there is a large amount of data information and the types of data involved, such as pictures, geographic locations, and videos. With big data, changes have taken place in many areas. In the process of carrying out management accounting, enterprises need to dig deeper into the core values of big data. They do not only simply introduce various hardware, but through innovative cloud computing technology, big data can be used to achieve better innovation in management accounting.

\section{Primary influence of big data on management accounting}

\subsection{Changes in the behavior of management accounting}

In the era of big data, companies' previous production factors, production tools, and production exchange methods have all changed. In these ways, management accounting has also changed ${ }^{[1]}$.

The first is about changes in production factors. In the traditional economic environment, labor, capital, and land resources are relatively scarce and limited in which these factors are not easy to change. However, knowledge has become the most critical element of enterprise products in the era of big data. In addition, 
with the continuous progress of the society, knowledge is becoming much more abundant while science and technology are constantly innovating.

The second is about changes in production tools. Under the traditional economic environment, production tools of enterprises mainly include machinery, natural forces, and human resources. In the era of big data, production tools have gradually evolved into the internet production system, which resulted in more advanced production tools.

The third is about changes in production exchange methods. In the era of big data, e-commerce has become the primary method of production exchange for enterprises. With the development of economic globalization, the operating mode of management accounting also needs to be adjusted accordingly. Under these conditions, the emergence of e-commerce promotes the production and exchange of enterprises in becoming more convenient and flexible.

\subsection{Changes in the management accounting process}

Big data has a particular impact on the economic behavior of enterprises, and it puts forward higher requirements in terms of management accounting behavior. Hence, this requires the design of a new management accounting process. The design process needs to be based on big data and is able to adapt to the development needs of the times. Only in this way, the essential advantages of companies can be fully utilized. However, if the designed management accounting process does not conform to the requirements of the times, then the use of the management accounting's advantages will be hindered, hence affecting the further development of the enterprise. Therefore, in the big data environment, companies must make changes to the management accounting process as soon as possible, as shown in Figure 1.

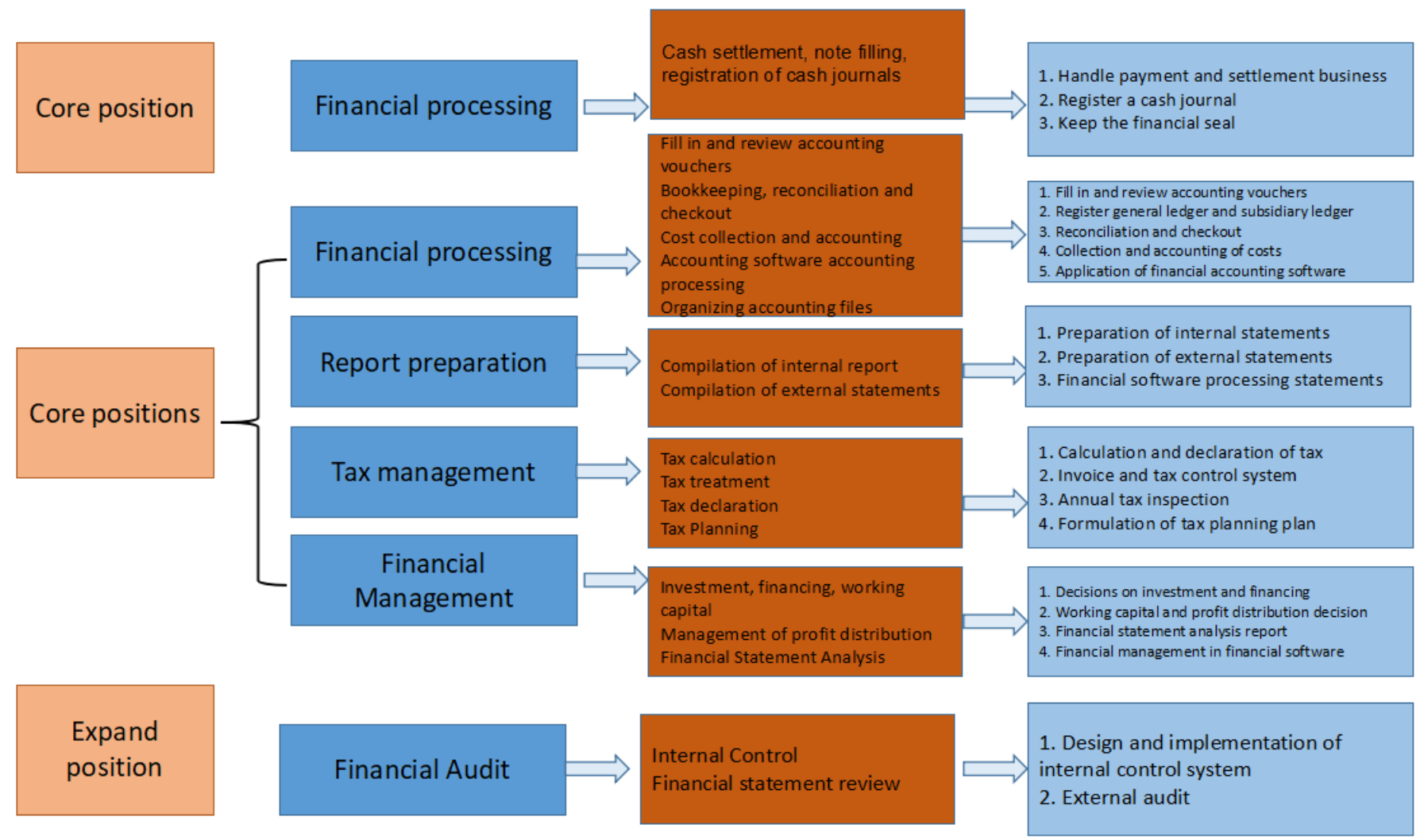

Figure 1. Management accounting process 
Data has become more diversified in the era of big data, showing uncertained and specialized characteristics in terms of management accounting requirements. Management accounting staffs need to keep up with the development of the times, promptly change past management accounting forms, and avoid being eliminated by social needs. In the era of big data, management accounting staffs need to pay attention in reorganizing the management accounting process so that the management accounting work can be carried out more smoothly and typically to better adapt to the development needs.

\subsection{Optimized the allocation of corporate resources}

The big data environment breaks the ordinary media. This economic model explores the value of big data through data collection and analysis to continuously embellish enterprises' economic activities, thereby improving their efficiency, and further promote the development of enterprises. This fact can also promote the transformation of enterprises from extensive growth into intensive growth.

In the era of big data, companies must recognize that high technology is an inevitable trend of corporate development, and when managers of companies implement management accounting work, they should change their goals based on the development needs of the times. Practical management accounting work aims to serve the sustainable development of enterprises and provide enterprises with critical information ${ }^{[2]}$. It can be seen that in the era of big data, the efficient development of management accounting has optimized the resource allocation of enterprises.

\section{Effective strategies to carry out management accounting efficiently under the big data environment}

\subsection{Raising the awareness of enterprise management to carry out management accounting}

Nowadays, the research on the theory and practice of management accounting in China is still relatively simple so there is still a long way to organically integrate big data into management accounting. In the era of big data, companies need to recognize the challenges faced by current corporate management accounting work based on the actual situation in China ${ }^{[3]}$. In the process of management accounting, there is a need to strengthen the summary of management accounting experiences that are suitable for big data in addition to vigorously promote and popularize related research results and materials. To this end, corporate management must establish a strong awareness of using big data to carry out management accounting work. For example, in order to encourage management staffs to establish the awareness of using big data, enterprises should frequently organize relevant competitions and training sessions for their staffs, as well as inviting well-known experts in the industry to provide professional trainings. At the same time, companies should also set up a unique column of knowledge about management accounting. In this way, the companies' management staffs would have a deeper understanding of big data and management accounting, hence strengthening their awareness of using big data to carry out management accounting work. Therefore, the development of corporate management accounting would become more efficient.

\subsection{Using cloud computing technology to strengthen the construction of management accounting information platform}

Under the big data environment, enterprises should use big data cloud computing technology to build management accounting information platforms to carry out management accounting work for analyzing massive amounts of data more conveniently and quickly. The steps in building an information platform are shown in Figure 2. Information platforms provide more accurate and reliable information, as well as valuable services for the sustainable development of enterprises in addition to prevent the real-time performance of management accounting information from being reduced. Under the big data environment, the emergence of various high technologies has also put forward higher requirements for the ability of 
enterprises to process management accounting information ${ }^{[4]}$. The introduction of big data cloud computing technology can realize the dynamic mining, analysis, processing, and storage of massive management accounting information, which is conducive to the improvement of corporate management accounting efficiency and the rational use of management accounting information. If companies want to analyze and process related data information more efficiently, building a management accounting information platform is an excellent way to achieve it.

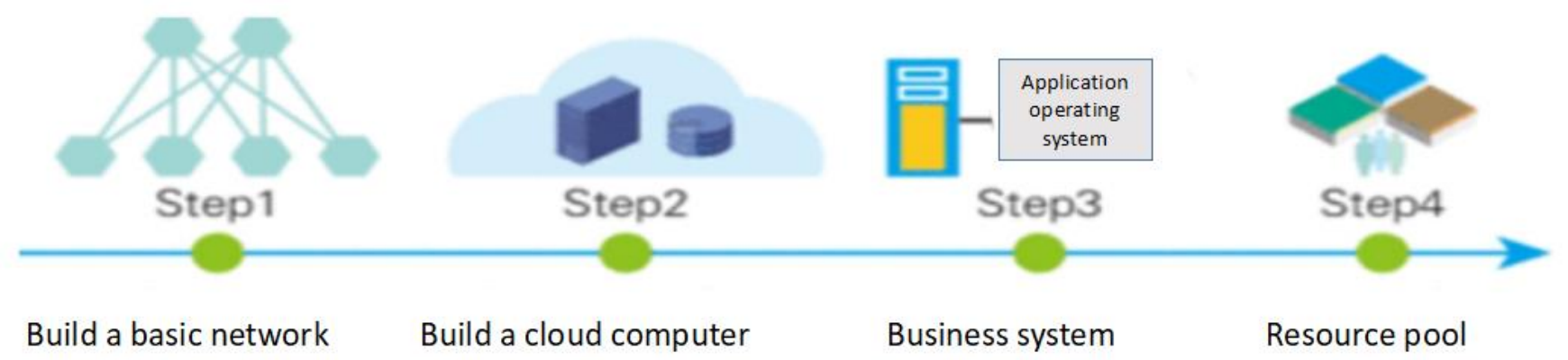

Figure 2. Steps to build a management accounting information platform

\subsection{Strengthening the security protection of big data information}

In the process of enterprise development, data information related to management accounting plays a significant value that cannot be neglected. It is necessary to strengthen security protection if companies want to give full play to the value of big data information. For example, in the process of carrying out management accounting with big data, an enterprise needs to improve the strength of mining and researching data related to management accounting as well as increase the investments of funds and talents [5]. In the cause of ensuring the security of these big data, the company needs to strengthen the use of key splitting and set access permissions to prevent malicious theft and tampering of these data. In addition, the company may need to purchase specialized software related to management accounting from suppliers. In order to further ensure data security, the company may also need to set different access permissions for their workers. In this way, to prevent the loss of relevant data and information, the staffs would not be able to perform processing beyond their authority on the management accounting data. The specific authority settings are shown in Figure 3.

Moreover, the company needs to strengthen the supervision of big data information in the management accounting work. Once the system discovers that there is illegal theft and tampering of data information, it will immediately detect the responsible person and impose severe punishment. In this way, the company's management and accounting staffs would have a strong awareness of data and information security precaution. All of them would then attach great importance to the protection of their rights to prevent their rights from being used by criminal elements, thereby causing damage to their work. 


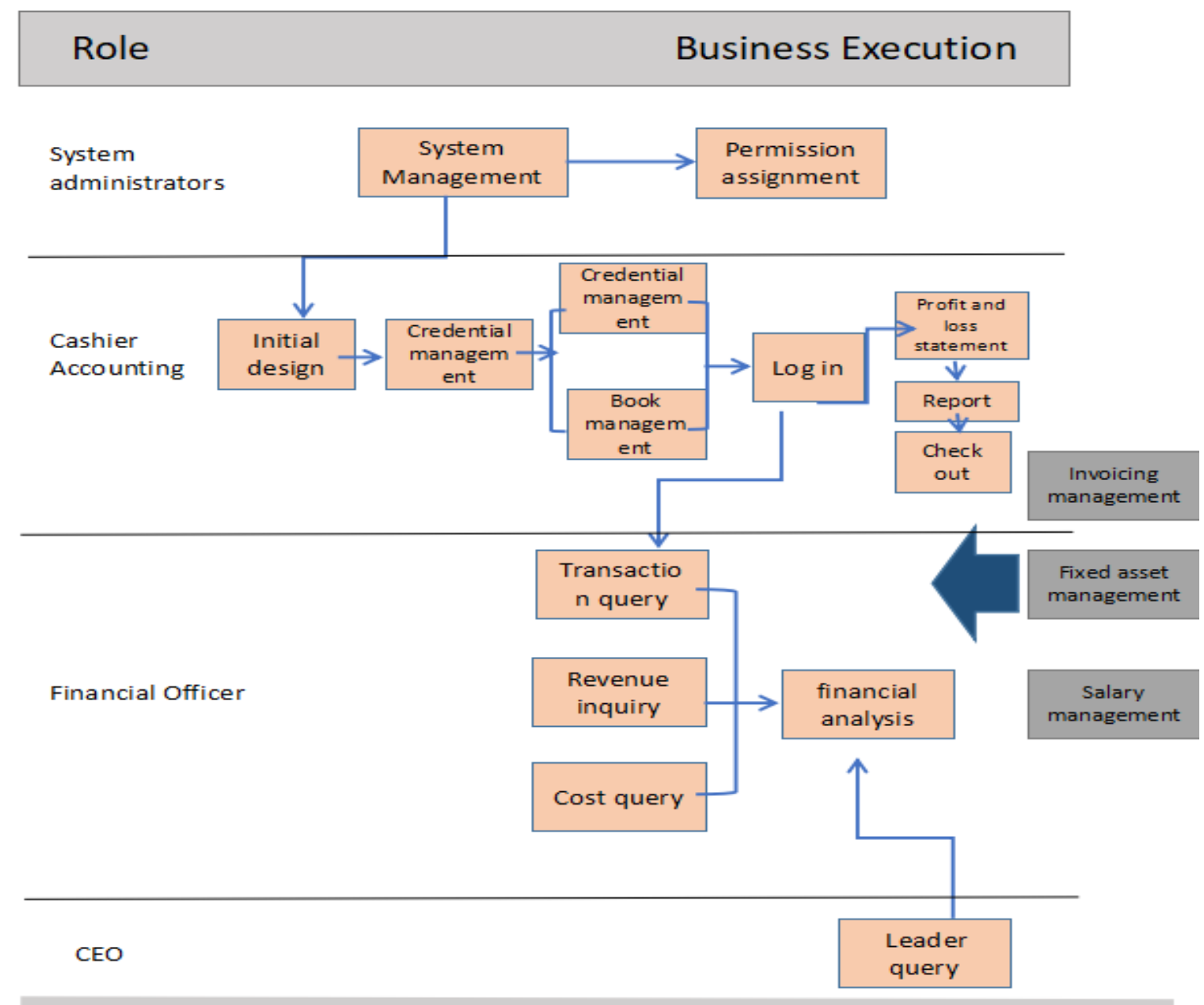

Figure 3. Authority settings in management accounting big data

Small and medium-sized enterprises are generally defined as smaller or entrepreneurial and growing enterprises, most of which are private enterprises. The managers of these enterprises have different management concepts, and their management efficiency as well as quality are more different. They are extremely vulnerable to the impact of the market and international economic fluctuations. In addition, the trade risks they bear are much higher than those of large enterprises. At the same time, small and mediumsized enterprises do not pay enough attention to financial administration and management, lack perfect internal control standards, and some even have financial administration and management loopholes, which affect the enterprises' credit, hence unable to successfully complete financing activities, such as loans. In addition, compared with large enterprises, small and medium-sized enterprises have a higher probability of high assets and liabilities, which also increases the difficulty for these enterprises to apply for financing from financial institutions.

\section{Conclusion}

To sum up, in the era of big data, companies need to fully understand the impact of big data on management accounting to carry out management accounting work and improve the corporate management's consciousness in using big data in carrying out their work. Companies should use big data cloud computing technology to strengthen the construction of management accounting information platforms, and at the same time, strengthen the security protection of big data information in management accounting to give full play to the critical value of big data in management accounting. 


\section{Disclosure statement}

The author declares that there is no conflict of interest.

\section{References}

[1] Qin N, 2021, Discussion on the Integrated Development of Corporate Financial Accounting and Management Accounting under the Background of the Internet. China Collective Economy, 4(18): 122-3.

[2] Du Y, 2021, The Design of Enterprise Management Accounting Framework in the Internet + Era. China Small and Medium Enterprises, 4(05): 154-5.

[3] $\mathrm{Qu} \mathrm{Y,} \mathrm{2021,} \mathrm{Conception} \mathrm{of} \mathrm{Management} \mathrm{Accounting} \mathrm{Informationization} \mathrm{Based} \mathrm{on} \mathrm{Cloud} \mathrm{Computing}$ Platform under Mobile Internet. Modern Marketing (Business Edition), 4(05): 56-7.

[4] Li C, 2021, Analysis of the Influence of Management Accounting Informatization on Traditional Accounting in the "Internet +" Era. Modern Marketing (Business Edition), 4(01): 108-9.

[5] Wang C, 2020, Research on the Transition of Internet Enterprise Financial Accounting to Management Accounting - Taking Y Company as an Example. China Management Information Technology, 23(24): $20-1$. 